\title{
Challenges in Economic Evaluation of Psoriatic Arthritis
}

Psoriatic arthritis (PsA) is a heterogeneous chronic inflammatory disorder of the peripheral joints, peripheral entheses, synovial sheaths of tendons, and spine associated with psoriasis. PsA is characterized by different clinical phenotypes and its course is variable ${ }^{1}$. Patients can also have gut ${ }^{2}$ and eye involvement ${ }^{3}$. In addition, patients with PsA or psoriasis have increased frequency of insulin resistance, obesity, type 2 diabetes, metabolic syndrome, hypertension, hyperlipidemia, and cardiovascular disease compared with the general population ${ }^{4}$. Recently, a new designation has been proposed with the aim to cover all these clinical situations: psoriatic disease ${ }^{5}$.

In the past, PsA was considered a rare and mild disease. The prevalence of psoriasis in the general population is currently estimated to be around $2 \%-3 \%$, with one-third of patients developing associated musculoskeletal manifestations. In the last 20 years, evidence has been gathered demonstrating that PsA is destructive and deforming in $40 \%-60 \%$ of patients, with joint damage emerging in the first years of the disease course ${ }^{6}$. It is believed that around $20 \%$ of patients with PsA develop a serious destructive disease. Patients with PsA suffer from functional impairment, decreased quality of life (QOL), and psychosocial disability, and have a significant increase in mortality versus the general population ${ }^{7,8}$

Therapies for PsA have been inadequate until recently. Nonsteroidal antiinflammatory drugs are useful in improving symptoms but have no effect on the progression of radiographic joint damage. Local corticosteroid injections may be of great aid in patients with persistent mono- or oligoarthritis but use of systemic glucocorticoid treatment is not supported by evidence. Traditional disease-modifying antirheumatic drugs (DMARD), which are the second-line treatment, are employed in PsA to control symptoms, but there is no evidence that they slow the progression of structural joint damage.

The introduction of tumor necrosis factor- $\alpha$ (TNF- $\alpha$ ) blocking agents has transformed the management of PsA. These drugs minimize signs and symptoms of inflammation, increase functional capacity and QOL, and decrease the progression rate of structural damage in peripheral joints ${ }^{9-11}$.
However, TNF- $\alpha$ blockers are very expensive and not directly accessible to all patients, depending on either a national health system or private insurance.

Illness costs in PsA were high even without these drugs and not much more different from those in other chronic inflammatory rheumatic diseases. Huscher and coworkers compared indirect and direct costs of illness in rheumatoid arthritis (RA), ankylosing spondylitis (AS), systemic lupus erythematosus (SLE), and PsA by evaluating the effect of disease duration, self-assessed health status, functional status, and demographic markers on the different cost domains ${ }^{12}$. The authors utilized data from a large number of patients aged $<65$ years from the National Database of the German Collaborative Arthritis Centres. Mean direct costs were $€ 4737$ per year in RA, $€ 3676$ in AS, $€ 3191$ in SLE, and $€ 3156$ in PsA. Taking into account indirect costs applying the human capital approach, total costs increased to $€ 15,637$ in RA, €13,513 in AS, €14,411 in SLE, and $€ 11,075$ in PsA while with the friction cost approach values were $€ 7899$, €7204, €6518, and €5570, respectively. Costs were strongly associated with functional status and disease duration. The authors concluded that costs were high in all 4 diseases and chiefly determined by functional capacity. In the Psoriatic Arthritis Cost Evaluation (PACE), an Italian cost-of-illness study on TNF- $\alpha$ inhibitors in patients with PsA with poor response to traditional DMARD, the cost per patient of PsA treatment for society in the 6 months prior to the start of anti-TNF- $\alpha$ therapy was $€ 1519.17^{13}$. This value corresponds to the approximate computation of probable cost per year of $€ 3100$, which differs from the total cost of $€ 11,075$ found by Huscher, et al in Germany ${ }^{12}$. The higher functional status and the shorter disease duration in the Italian study together with different types of costs may account for the differences. A recent study from Hungary ascertained total costs for PsA as €5574/patient/year ${ }^{14}$. Mean direct medical costs accounted for $€ 1876$, direct nonmedical costs for €794, and indirect costs for €2904.

Costs are also high for patients with only skin lesions ${ }^{15-17}$. In 2006, Javitz and coworkers evaluated the direct cost of medical care for psoriasis and PsA in US adults utilizing a limited societal perspective ${ }^{15}$. Indirect

See Socioeconomic burden of PsA in Hong Kong, page 1214

Personal non-commercial use only. The Journal of Rheumatology Copyright (C) 2010. All rights reserved. 
and intangible costs were not taken into account. Direct medical costs (outpatient and office procedures, outpatient and physician office visits, prescription medications, over-the-counter medications and hospitalizations) were acquired from privately and publicly accessible databases and from the literature. An estimation of annual costs was applied to the US population in 1997 based on 1997 dollars. The total cost for about 1.4 million patients with psoriasis or PsA was $\$ 649.6$ million. Outpatient physician visits accounted for $\$ 86.6$ million, dermatologic prescription drugs for $\$ 147.9$, photochemotherapy for $\$ 27.4$, over-the-counter medications for $\$ 357.2$, and hospitalizations for $\$ 30.5$ million. Total annual costs were about $\$ 452$ per person with clinically significant psoriasis or almost $\$ 718$ per person with clinically significant and active psoriasis. The total annual cost in the above study ${ }^{15}$ was less than the cost of $\$ 1.09$ billion and $\$ 4.32$ billion found earlier by Kraning and Odland ${ }^{16}$ and Krueger, et $a l^{17}$, respectively. The major reason for these differences was the lower number of hospitalization days compared with the previous years due to availability of better drugs for improving symptoms and to higher use of day-treatment clinics. Ackermann and Kavanaugh in their review of the economic burden of PsA emphasized the main weaknesses of this study ${ }^{15}$ : the lack of assessment of indirect costs and the absence of separate rates for PsA in the cost evaluation ${ }^{18}$. Actually, indirect costs are very high in PsA, especially as a result of productivity losses due to sick leave and extensive work disability.

In this issue of The Journal, Zhu and coworkers report the results of their study on direct and indirect costs of PsA in Hong Kong ${ }^{19}$. The average annual direct and indirect costs were \$4141 and \$3127 (2006 US dollars), respectively. They found that pain and function were significantly associated with costs and suggest that treatments to reduce pain and restore function are highly likely to reduce costs incurred by patients with PsA. However, no patient participating in the study was treated with TNF- $\alpha$ blockers since these drugs are not within the Hong Kong government's reimbursement system, and patients have to pay for treatment themselves.

The study by Zhu and colleagues raises a question: should a public health system reimburse anti-TNF- $\alpha$ therapy to reduce the costs of treatment of PsA? In other words, are anti-TNF- $\alpha$ inhibitors cost-effective? The cost-effectiveness studies on anti-TNF- $\alpha$ blocking agents in PsA performed so far have demonstrated that these drugs are cost-effective for both the cutaneous and musculoskeletal manifestations of psoriatic disease ${ }^{20-25}$. Most of these studies were carried out using data obtained from published international clinical trials ${ }^{20-24}$ and one was performed in a clinical practice setting ${ }^{13}$. In the PACE study, 107 patients from 9 Italian rheumatology centers, with different forms of PsA that responded inadequately to conventional treatment, were given anti-TNF- $\alpha$ agents, mainly etanercept ${ }^{13}$. Cost (expressed in 2007 Euros) and utility (measured using EuroQOL) before and after start of TNF- $\alpha$ therapy were evaluated to estimate the incremental quality-adjusted life year (QALY) gained and calculate a cost-effectiveness acceptability curve. The study was performed from the viewpoint of the community, the largest entity that can have a point of view, and which includes the Italian third-party payer (the National Health System), patients, and their families. After 12 months of anti-TNF- $\alpha$ therapy, there was a significant escalation of direct costs due to the increased drug cost of anti-TNF- $\alpha$ agents, which was only partially compensated by the reduction of indirect costs. In the last 6 of 12 months of anti-TNF- $\alpha$ therapy, direct costs increased by $€ 5052$, the cost for the Italian National Health System by $€ 5044$, and the social cost by $€ 4638$. However, a gain of 0.12 QALY produced a cost per QALY gained of $€ 40,876$ for the Italian National Health System and of €37,591 for society. The acceptability curve demonstrated that there would be a $97 \%$ likelihood that anti-TNF- $\alpha$ therapy would be valued as cost-effective at the willingness-to-pay threshold of $€ 60,000$ per QALY gained suggested for Italy. One of the values of the Italian study was the demonstration that anti-TNF- $\alpha$ therapy is cost-effective in the short term in clinical practice.

In conclusion, the study by Zhu, et $a l^{19}$ underlines that the socioeconomic burden of PsA is considerable and is not different from that of RA and AS. Anti-TNF- $\alpha$ agents, which are more expensive than conventional drugs, reduce disease activity and improve function and QOL and are, therefore, able to reduce direct and indirect costs due to PsA. Recent studies have shown their cost-effectiveness. It is desirable that other pharmacoeconomic studies be performed on these drugs in the near future. However, it is essential that these agents be less costly. The expected introduction of other biologic drugs together with the influence of market forces could lower their costs.

IGNAZIO OLIVIERI, MD,

Consultant, Director,

Rheumatology Department of Lucania,

San Carlo Hospital of Potenza and Madonna

delle Grazie Hospital of Matera, Potenza and Matera;

SALVATORE D'ANGELO, $\mathrm{MD}$,

Rheumatology Department of Lucania,

San Carlo Hospital of Potenza and Madonna delle Grazie Hospital of Matera,

Researcher, PhD Scholarship in Health Sciences, University of Molise, Campobasso;

CARLO PALAZZI, MD,

Senior Investigator;

ANGELA PADULA, $\mathrm{MD}$,

Senior Registrar,

Rheumatology Department of Lucania,

San Carlo Hospital of Potenza and Madonna

delle Grazie Hospital of Matera,

Potenza and Matera, Italy Personal non-commercial use only. The Journal of Rheumatology Copyright @ (2010. All rights reserved. 
Address correspondence to Dr. Olivieri;

E-mail: ignaziolivieri@tiscalinet.it

\section{REFERENCES}

1. Gladman DD. Psoriatic arthritis. In: Harris ED Jr, Budd RC, Firestein GS, Genovese MC, Sargent JS, Ruddy S, Sledge CB, editors. Kelley's textbook of rheumatology. 7th ed. Philadelphia: Elsevier Saunders; 2005:1155-64.

2. Scarpa R, Manguso F, D'Arienzo A, D'Armiento FP, Astarita C, Mazzacca G, et al. Microscopic inflammatory changes in colon of patients with both active psoriasis and psoriatic arthritis without bowel symptoms. J Rheumatol 2000;27:1241-6.

3. Queiro R, Torre JC, Belzunegui J, González C, De Dios R, Unanue $\mathrm{F}$, et al. Clinical features and predictive factors in psoriatic arthritis-related uveitis. Semin Arthritis Rheum 2002;31:264-70.

4. Tam LS, Tomlinson B, Chu TT, Li M, Leung YY, Know LW, et al. Cardiovascular risk profile of patients with psoriatic arthritis compared to controls - the role of inflammation. Rheumatology 2008;47:718-23.

5. Scarpa R, Ayala F, Caporaso N, Olivieri I. Psoriasis, psoriatic arthritis, or psoriatic disease? J Rheumatol 2006;33:210-2.

6. Gladman DD, Stafford-Brady F, Chang CH, Lewandowski K, Russell ML. Longitudinal study of clinical and radiological progression in psoriatic arthritis. J Rheumatol 1990;17:809-12.

7. Gladman DD. Disability and quality of life considerations. Psoriatic arthritis. In: Gordon GB, Ruderman E, editors. Psoriatic and psoriatic arthritis: an integral approach. Heidelberg: Springer-Verlag; 2005:118-23.

8. Gladman DD, Farewell VT, Wong K, Husted J. Mortality studies in psoriatic arthritis: results from a single outpatient center. II. Prognostic indicators for death. Arthritis Rheum 1998;41:1103-10.

9. Mease PJ, Kivitz AJ, Burch FX, Siegel EL, Cohen SB, Ory P, et al. Etanercept treatment of psoriatic arthritis: safety, efficacy, and effect on disease progression. Arthritis Rheum 2004;50:2264-72.

10. Antoni CE, Kavanaugh A, van der Heijde D, Beutler A, Keenan G, Zhou B, et al. Two-year efficacy and safety of infliximab treatment in patients with active psoriatic arthritis: findings of the Infliximab Multinational Psoriatic Arthritis Controlled Trial (IMPACT). J Rheumatol 2008;35:869-76.

11. Mease PJ, Gladman DD, Ritchlin CT, Ruderman EM, Steinfeld SD, Choy EH, et al. Adalimumab for the treatment of patients with moderately to severely active psoriatic arthritis: results of a double-blind, randomized, placebo-controlled trial. Arthritis Rheum 2005;52:3279-89.

12. Huscher D, Merkesdal S, Thiele K, Zeidler H, Schneider M, Zink A; German Collaborative Arthritis Centres. Cost of illness in rheumatoid arthritis, ankylosing spondylitis, psoriatic arthritis and systemic lupus erythematosus in Germany. Ann Rheum Dis
2006;65:1175-83

13. Olivieri I, de Portu S, Salvarani C, Cauli A, Lubrano E, Spadaro A, et al. The psoriatic arthritis cost evaluation (PACE) study: a cost-of-illness study on tumour necrosis factor inhibitors in psoriatic arthritis patients with inadequate response to conventional therapy. Rheumatology 2008;47:1664-70.

14. Brodszky V, Bálint P, Géher P, Hodinka L, Horváth G, Koó E, et al. Disease burden of psoriatic arthritis compared to rheumatoid arthritis, Hungarian experiment. Rheumatol Int April 192009 [Epub ahead of print].

15. Javitz HS, Ward MM, Farber E, Nail L, Vallow SG. The direct cost of care for psoriasis and psoriatic arthritis in the United States. J Am Acad Dermatol 2002;46:850-60.

16. Kraning KK, Odland GF. Psoriasis. J Invest Dermatol 1979; 73:402-13.

17. Krueger GG, Bergstresser PR, Lowe NJ, Voorhees JJ, Weinstein GD. Psoriasis. J Am Acad Dermatol 1984;11:937-47.

18. Ackermann C, Kavanaugh A. Economic burden of psoriatic arthritis. Pharmacoeconomics 2008;26:121-9.

19. Zhu TY, Tam LS, Leung YY, Kwok LW, Wong KC, Yu T, et al. Socioeconomic burden of psoriatic arthritis in Hong Kong: direct and indirect costs and the influence of disease pattern. J Rheumatol 2010;37:1214-20.

20. Bansback NJ, Ara R, Barkham N, Brennan A, Fraser AD, Conway $\mathrm{P}$, et al. Estimating the cost and health status consequences of treatment with TNF antagonists in patients with psoriatic arthritis. Rheumatology 2006;45:1029-38.

21. Woolacott N, Bravo Vergel Y, Hawkins N, Kainth A, Knadjesari Z, Misso K, et al. Etanercept and infliximab for the treatment of psoriatic arthritis: a systematic review and economic evaluation. Health Technol Assess 2006;10:1-239.

22. Kavanaugh A, Antoni C, Mease P, Gladman D, Yan S, Bala M, et al. Effect of infliximab therapy on employment, time lost from work, and productivity in patients with psoriatic arthritis. J Rheumatol 2006;33:2254-9.

23. Bravo Vergel Y, Hawkins NS, Claxton K, Asseburg C, Palmer S, Woolacott N, et al. The cost-effectiveness of etanercept and infliximab for the treatment of patients with psoriatic arthritis. Rheumatology 2007;46:1729-35.

24. Sizto S, Bansback N, Feldman SR, Willian MK, Anis AH. Economic evaluation of systemic therapies for moderate to severe psoriasis. Br J Dermatol 2009;160:1264-72.

25. Olivieri I, Mantovani LG, D’Angelo S, Padula A, de Portu S. Psoriatic arthritis: pharmacoeconomic considerations. Curr Rheumatol Rep 2009;11:263-9.

J Rheumatol 2010;37:1086-8; doi:10.3899/jrheum.100164 